\title{
EXPROPRIAÇÃO DO DIREITO À CIDADE E POSIÇÕES POLÍTICAS DE ENFRENTAMENTO DO MOVIMENTO NACIONAL DE LUTA PELA MORADIA
}

\section{EXPROPRIATION OF THE RIGHT TO THE CITY AND THE POLITICAL POSITIONS OF THE NATIONAL MOVEMENT FOR THE RIGHT TO HOUSING TO CONFRONT IT}

\author{
Mariana Diniz Bittencourt Nepomuceno ${ }^{152}$
}

\begin{abstract}
Resumo
O presente trabalho tem por objetivo central analisar os problemas da crise de moradia na cidade do Rio de Janeiro através dos elementos contra-hegemônicos da dinâmica de luta e resistência do um movimento popular: o Movimento Nacional de Luta pela Moradia (MNLM). Utiliza-se, para tanto, a Teoria Marxista da Dependência na tentativa de apreender as leis tendenciais do capitalismo e como as mesmas se estruturam, se agudizam e se manifestam mormente via instituição estatal - na expropriação do direito à moradia sob a perspectiva da relação dialética entre imperialismo e dependência.
\end{abstract}

Palavras-chave: Direito à cidade. Movimentos populares urbanos. Dinâmica de luta e resistência. Movimento Nacional de Luta pela Moradia.

\begin{abstract}
This article analyzes the housing crisis in the city of Rio de Janeiro through contra hegemonics elements of the fight dynamics and resistance of a popular movement: the National Movement of Fight for the Right of Housing (MNLM/Brasil). Through in an attempt to apprehend how capitalist tendency laws and how they are structured, sharpen and manifest, if they increase and appears - mainly via state institution - in the expropriation of the right to housing under the perspective of the dialectics relation between imperialism and dependence.
\end{abstract}

Keywords: Right to the city. Urban popular movements. Fight dynamics and resistance. National Movement for the Fight for Housing.

\footnotetext{
152 Pesquisadora militante de práticas educativas não-formais no interior de movimentos populares. Graduada em Letras e Pedagogia, Mestre em Educação Intercultural (Universidade de Lisboa) e Educação em Valores e para a Cidadania (Universidade de Barcelona). Doutoranda em Educação (Universidade Federal Fluminense). 0 artigo é resultado de uma pesquisa (em andamento) para a realização de tese no programa de doutorado em Educação da Universidade Federal Fluminense. E-mail: marydniz3@gmail.com. Telefone: (21) 997991377. ORCID (https://orcid.org/0000-0003-4549-8554).
} 


\section{RevistAleph}

\section{Introdução}

A partir deste solo social concreto (déficit habitacional) e articulando luta de classes e o papel do Estado, pretende-se construir um conhecimento crítico sobre os protagonistas do sujeito coletivo organizado pelo Movimento Nacional de Luta pela Moradia (MNLM), a classe a que estão vinculados, o que disputam junto às agências do Estado e os elementos para a transformação social presentes nesta organização popular. O trabalho está estruturado da seguinte forma: resgate histórico e atualidade da crise de moradia na cidade do Rio de Janeiro, abordando: divisão social do seu espaço físico, desenvolvimento do capitalismo a partir do estabelecimento destas fronteiras urbanas e criminalização da pobreza; histórico e atualidade da resistência popular organizada às remoções/demolições, à mercantilização do espaço urbano e às novas formas de expropriação; histórico, características e atuação do MNLM dentro das relações de força atuais; e dimensão político-pedagógica das práticas de sociabilidade interna presentes no mutirão para a construção da Ocupação Manoel Congo, coordenada pelo Movimento.

\section{Resgate histórico da crise de moradia na cidade do Rio de Janeiro}

Longe de suprimir as diferenças de fato, o Estado existe até apenas enquanto as pressupõe Marx (1989, p.12).

A crise de moradia na cidade do Rio de Janeiro não é recente. De fato, a partir da segunda metade do século XIX (especialmente entre os anos de 1872 a 1890), a urbanização provocou grandes transformações no espaço imobiliário carioca. Neste processo, explícito fica como a economia se autonomiza e impõe regras "naturalizadas" ao ser social: a dinâmica urbana foi alterada pelo processo histórico de desenvolvimento econômico. Com a expansão do complexo cafeeiro, a incipiente industrialização começa a modificar o mercado e, consequentemente, o espaço brasileiro, consolidando indústrias nas grandes cidades e alterando redes de integração no país (FORNAZIN, 2014) - especialmente São Paulo e Rio de Janeiro. Na capital federal da República Velha, a política de remodelação do espaço urbano 


\title{
RevistAleph
}

promovido por Pereira Passos, então prefeito da cidade (1902-1906), pretendia torná-la símbolo de modernidade, ordenamento racional e progresso econômico. O Rio de Janeiro transformou-se assim em um grande canteiro de obras a partir das quais se pretendia "embelezar" a cidade aos moldes parisienses com o objetivo de atrair investidores estrangeiros. A respeito do processo de urbanização no Brasil, Milton Santos (1995, p.96) afirma que:

\begin{abstract}
Com diferença de grau e de intensidade, todas as cidades brasileiras exibem problemáticas parecidas. O seu tamanho, tipo de atividade, região em que se inserem etc. são elementos de diferenciação, mas em todas elas problemas como os do desemprego, da habitação, dos transportes, do lazer, da água, dos esgotos, da educação e saúde, são genéricos e revelam enormes carências. Quanto maior a cidade, mais visíveis se tornam essas mazelas. Mas essas chagas estão em toda parte. Isso era menos verdade na primeira metade deste século, mas a urbanização corporativa, isto é, empreendida sob o comando dos interesses das grandes firmas, constitui um receptáculo das consequências de uma expansão capitalista devorante dos recursos públicos, uma vez que estes são orientados para os investimentos econômicos, em detrimento dos gastos sociais.
\end{abstract}

Observou-se, à época, uma gigantesca expansão da população urbana (aumento de cerca de $90 \%$ ), no qual o parque domiciliar não acompanhou (crescimento de 62\%) . A partir de então, as condições de vida na cidade tornam-se cada vez mais árduas. Entre 1890 e 1906 a crise de moradia se agrava. A densidade domiciliar passa de 7,3 para 9,8 pessoas por moradia. Em 1930, 50\% da população já residia em cortiços precários e insalubres . Forja-se, então, uma ideologia urbanista que sustenta políticas de remodelagem "racional" do espaço, principalmente de um discurso sanitarista - que serviu, essencialmente, para camuflar um problema político como uma questão técnica.

Com a demolição dos cortiços e os despejos através das inciativas estatais como a "Guerra de Picaretas" e o "Bota Abaixo" surgem as primeiras ocupações dos morros da cidade (favelas). Inicia-se assim a divisão social também no espaço físico. Criminalizam-se construções de moradias pobres no centro carioca através do Decreto 391 (Regulamento para a Construção, Reconstrução, Acréscimos e Consertos em Prédio, de 10 de fevereiro de 1903). Entretanto, a necessidade de uma mão de obra barata que movesse o novo complexo industrial fez com que tal Decreto abrisse uma exceção para a construção em áreas centrais porém desprivilegiadas da cidade, estabelecendo, em seu Artigo 36, que "[...] os barracões toscos não serão permitidos, seja qual for o pretexto de que lance mão para obtenção de 


\section{RevistAleph}

licença, salvo nos morros que ainda não tiverem habitações, e mediante licença" (SANTOS, 2011).

Visualizando o Estado como terreno de luta, pode-se enxergar a atuação da classe dominante que se utiliza do mesmo como instrumento na disputa hegemônica: a cada "ganho" da classe trabalhadora - neste caso, a construção de moradias populares na região suburbana -, nega-se um de seus direitos - como, por exemplo, o acesso aos serviços básicos de saneamento, saúde e educação. Os grupos dominantes vão "moldando" a cidade de acordo com seus interesses de forma que o território não é mais um espaço natural, mas socialmente produzido. Silveira (2014, p.71), em estudo sobre a luta pela moradia e pela reforma urbana, sustenta, acertadamente, que:

Ao considerarmos o processo de formação urbana brasileira (...), nos fica nítido como se dá, na prática social, a produção do espaço comandada pela dinâmica territorial decorrente da lógica de estruturação do capitalismo sob as cidades, compreendida pelos grandes empresários não como espaço de bem viver em comunidade, mas sim enquanto fonte de lucros e exploração da classe trabalhadora. Sendo o solo urbano e a própria moradia, mercadorias de difícil acesso para amplas parcelas da população, explica-se os porquês das ocupações de terras urbanas terem se tornado parte inerente do modelo de urbanização vigente no País, representando mais a regra do que a exceção das formas de provisão de habitação.

Visualiza-se aqui a dinâmica capitalista da concentração, centralização, acumulação e apropriação que busca assenhorar-se de espaços para convertê-los em mercadoria e consequentemente - novas formas de extração de valor. A normatização do espaço urbano segundo essa dinâmica é acompanhada pelo processo de criminalização da apropriação da área central pelos pobres (e criminalização da pobreza) que fez com que a população das favelas aumentasse consideravelmente. Neste processo, fica clara a forma como a mercantilização e a expropriação do espaço urbano constituem vetores de expansão do capitalismo, convertendo os meios de existência em mecanismos de subjugação dos trabalhadores. Fornazin (2014, p.9) afirma que, a partir de então,

(...) a pobreza foi entendida não como resultado das condições estruturais do mercado, mas como uma má adaptação dos migrantes à vida urbana e passou a ser considerada como questão social de responsabilidade do Estado, surgindo as primeiras teorias sobre a marginalidade. 


\title{
RevistAleph
}

Seria, assim, um problema de ordem individual, estigmatizada pela ideologia sanitarista e desenvolvimentista, vista como sinônimo de doenças infectocontagiosas representação social dos setores empobrecidos, em voga até os dias atuais.

\section{Histórico e atualidade da resistência popular organizada à crise de moradia}

Considerando a sociedade civil como espaço privilegiado para visualizar a luta de classes - seja na forma de integração ou de contestação à ordem social vigente - analisamos, a seguir e de forma sucinta, a história e a situação atual dos movimentos populares urbanos organizados em torno da luta contra a mercantilização do espaço urbano e às formas de expropriação capitalista na cidade do Rio de Janeiro. Nesse sentido, concordamos com Botega (2004, p. 60) quando afirma ser:

\begin{abstract}
A partir desta relação dialética ocorrida entre a contradição estrutural em que se inserem os serviços urbanos colocados sob a lógica da "cidade do capital", e a reação das classes populares na luta pelo "direito à cidade", que devemos entender a formação dos movimentos populares urbanos.
\end{abstract}

Nos anos de 1940 inicia-se, no Rio de Janeiro, um tipo ainda incipiente de organização popular lutando pelo direito à moradia. As camadas empobrecidas resistem às políticas de remoção nos morros do Cantagalo, Pavão-Pavãozinho e Babilônia. Em 1947 surgem associações de moradores, em 1954 é fundada a União dos Trabalhadores Favelados e em 1959 a Coligação dos Trabalhadores Favelados (CTF). Tais organizações reivindicavam, essencialmente, o direito à moradia. Já em 1963 cria-se a FAFEG (Federação das Associações de Moradores do Estado da Guanabara, hoje FAFERJ), reunindo 28 associações em torno de uma federação contra a política de remoções. Os debates e embates políticos são interrompidos com o Golpe de 1964. Retomam-se em 1975, já com o apoio dos setores progressistas da Igreja Católica. Nos anos subsequentes o discurso liberalista globalizante da "eficácia" eclipsa os debates uma vez mais, desarticulando os movimentos populares urbanos.

Segundo Gohn (1991), é precisamente a partir da década de 1970 que se observa, no Brasil - e na América Latina em geral -, o ressurgimento de um grande número de movimentos sociais. Alguns destes apresentam questões específicas e peculiares, como os movimentos ecológicos, pacifistas, de igualdade racial e de combate à homofobia. Outros 


\section{RevistAleph}

caracterizam-se por seu corte classista (sindicais, urbanos, rurais), surgindo a partir das camadas populares e lutando por bens de consumo coletivos e acessíveis. No que se refere aos movimentos de classe urbana, as reivindicações básicas referem-se, principalmente, à infraestrutura, educação, transporte e habitação. Àquela época, as lutas eram isoladas, reivindicando, por exemplo, serviços de luz, água, transporte e creches - dentre outros. Se, em um primeiro momento, esses diversos grupos sociais, ainda desarticulados, limitavam sua pauta essencialmente ao direito à habitação, ao constituírem-se como movimento popular nacionalmente estruturado passam a exercer uma pressão política, por meio de ocupações, para que a luta pela moradia englobe também direitos básicos urbanos, seus serviços, equipamentos, etc. - em resumo, o direito à cidade.

Para Harvey (2009), o direito à cidade não é simplesmente o direito ao que já existe na cidade, mas o direito de transformar a cidade em algo diferente, de forma radical. Quando se olha para a história, percebe-se "que as cidades foram regidas pelo capital, mais que pelas pessoas. Assim, nessa luta pelo direito à cidade haverá também uma luta contra o capital" (idem). De fato, alguns movimentos populares urbanos que hoje atuam na América Latina reivindicam, em seus projetos transformadores, não apenas uma mera reforma nos campos em que atuam, mas apresentam um caráter eminentemente anticapitalista.

No final da década de 1970 os movimentos se aglutinam em organizações locais, obtendo apoio de organizações do campo democrático-popular, da esquerda e de alguns setores liberais que também viam no Estado seu principal opositor, lutando contra a ditadura militar. A conjuntura nacional da década seguinte faz com que a partir de 1980 esses movimentos se transformem. A ineficiência do poder do Estado de manter os índices econômicos da década anterior, graças a diversos fatores como a crise do petróleo e o aumento exacerbado da dívida externa acabam por revelar o esgotamento daquele modelo de crescimento e deslegitimar politicamente os governantes. Recessão, altos índices de desemprego, arrocho salarial, extremada concentração de renda e aceleração intensa do processo de exclusão social são alguns dos fatores devastadores de uma economia voltada para o mercado externo os quais atingem diretamente a classe dominada brasileira. Observase, mormente no período dos governos de Margareth Thatcher (1979-90), Ronald Reagan (1980-88) e Augusto Pinochet (1973-89), uma intensificação da forma de extração de valor 


\section{RevistAleph}

direta sobre a massa crescente de desempregados, a "socialização" do processo de trabalho em condições ainda mais rebaixadas.

A estratégia de modernização autoritária mostrou-se completamente ineficaz no que se refere à redução das desigualdades sociais e à promoção de um mínimo desenvolvimento social que integrassem as classes populares e as mantivessem amorfas sob o jugo da classe dominante. Para Gohn (1991), apesar de este período representar o desmonte dos direitos civis básicos e a extinção de políticas públicas sociais também suscitou a necessária desconstrução de alguns mitos, como a crença no nacionalismo, no progresso ilimitado (baseado no modelo de acumulação vigente) e na estratégia de conciliação entre classes como forma de fazer política. Assim, alguns movimentos populares se fortalecem, operando um salto qualitativo, unificando suas demandas localizadas ao redor de setores problemáticos no âmbito social. Opera-se uma construção de identidades por meio das semelhanças pelas carências sofridas, pelo desejo de se ter acesso aos direitos mínimos dos indivíduos e grupos enquanto cidadãos. As reivindicações isoladas dão lugar a formas agregadas mais amplas das demandas populares.

\section{MNLM e relações de força atuais}

Pretende-se que existam sempre governantes e governados ou pretende-se criar as condições nas quais a necessidade dessa divisão desapareça? Gramsci (In LIGUORI \& VOZA, 2017)

O Movimento Nacional de Luta pela Moradia (MNLM) surge no interior dessas lutas como movimento social urbano que reivindica, principalmente, uma moradia digna para aqueles que habitavam favelas, cortiços ou que simplesmente não tinham onde morar, dada a distribuição desigual e injusta do espaço urbano. Surge, portanto, da necessidade de se criar uma organização nacional capaz de articular e dirigir a luta pela Reforma Urbana. Pode-se afirmar que o MNLM encontra suas origens históricas recentes nas ações de caravanas de moradia à Brasília com o objetivo de cobrar do governo federal as reivindicações de uma imensa massa de sem-tetos, mutuários do Sistema Financeiro da Habitação, inquilinos e favelados, então representados por associações, federações estaduais e movimentos locais. A realização do I Seminário Nacional de Moradia Popular foi promovido pela CNBB 


\section{RevistAleph}

(Confederação Nacional de Bispos do Brasil), a Pastoral da Moradia de São Paulo e os trabalhos de entidades de assessoria aos movimentos populares, sobretudo da ANSUR (Articulação Nacional do Solo Urbano). Outro marco histórico recente que pode ser considerado um vetor para a articulação nacional dos diversos movimentos populares por moradia foi a Emenda Popular da Reforma Urbana apresentada pelo Fórum Nacional de Reforma Urbana, durante o processo de elaboração da atual Constituição Federal de 1988. Mobilizando entidades da sociedade civil de vários estados brasileiros, chegou a coletar 165 mil assinaturas por todo o país, promovendo a união dos movimentos de moradia e, inclusive, iniciando um processo de conscientização de seus integrantes sobre o direito não apenas à moradia, mas à cidade (seus serviços e estruturas).

Oficialmente, o MNLM foi fundado em 1990 no I Encontro Nacional dos Movimentos de Moradia, realizado na cidade de Goiânia (GO), com representação de 13 Estados da federação. O objetivo central era universalizar a luta dos excluídos, constituindo uma nova compreensão do direito de morar baseada na busca de uma cidade onde a habitação, a saúde, a educação, ao saneamento básico, a infraestrutura urbana, ao transporte, ao trabalho e ao lazer, possa ser usufruída por todos, segundo suas necessidades geridas por todos, segundo sua disponibilidade e interesses para o presente e para as futuras gerações. Atuando em 18 estados, o MNLM conta, hoje, coordenações municipais, estaduais e uma nacional, com representantes eleitos pelos seus próprios integrantes. Qualquer pessoa do MNLM pode candidatar-se a delegado, contanto que atenda a um dos seguintes critérios: ter ao menos seis meses de atuação no Movimento, ser morador de uma ocupação ou compor algum núcleo (como o de regularização fundiária, formação, juventude e mulheres). A principal forma de luta do MNLM são as ocupações a prédios públicos abandonados e ociosos, ou seja, aqueles que não atendem à função social da propriedade (constitucionalmente garantida). Segundo os coordenadores do Movimento ${ }^{153}$, seu objetivo principal é o de:

(...) estimular a organização e articulação da classe trabalhadora na busca da unidade de suas lutas, pela conquista de uma política habitacional de interesse social com reforma urbana, sob o controle dos trabalhadores, que garanta a universalização dos direitos sociais, contribuindo para a construção de uma sociedade socialista, igualitária e democrática.

\footnotetext{
${ }^{153}$ Retirado de http://mnlmrj.blogspot.com/p/apresentacao.html.
} 


\section{RevistAleph}

Porém, na contramão da lógica coletivista do MNLM, vivemos, atualmente, em uma sociedade de valorização do individualismo, na qual as utopias coletivas foram diluídas, fragmentadas e privatizadas: é no âmbito individual que as soluções são pensadas, ainda que os problemas sejam socialmente (globalmente) produzidos. A dificuldade de generalizar as experiências individuais em reivindicações sociais, de convertê-las em questões de uma política comum e, em última instância, de reformular a ótica coletiva sobre as utopias privatizadas da vida social é a principal condição (e primeira consequência) do modo de pertencimento e de participação do sujeito na atual ordem social - e o estorvo "capital" para a construção de uma nova cultura de participação popular ativa, baseada em uma concepção de mundo crítica, coerente e unitária.

Como vimos, a partir do início do século XX, frente ao agravamento do processo de pauperização das classes populares e das condições de alienação a que estavam submetidas, o que ocorre é o início da organização dos segmentos mais conscientes dos trabalhadores e de pensadores críticos orgânicos nas mais diversas formas, gerando aquilo que seria a construção de uma identidade coletiva de classe. Surgem assim sindicatos, irmandades secretas, associações de ajuda mútua, cooperativas, etc., editando periódicos e folhetins diversos, construindo uma crescente "sociedade civil proletária" (ABREU, 2008, p.99) que, mais do que agitar aos trabalhadores para a luta, promoviam uma nova forma de relacionamento social com base em uma sobrevivência compartilhada, coletivizada e progressivamente politizada em suas relações conflitivas com a sociedade civil especificamente burguesa (fundada no contrato individual). Tais organizações procuravam não somente a união dos trabalhadores por categoria ou profissão em defesa de seus interesses corporativos, mas privilegiavam sobretudo a unidade intelectual, ética e política de classe, constituindo uma vontade coletiva para enfrentar as dificuldades materiais e as condições de miséria e degradante. A sociedade civil desenvolve-se dividida entre duas formas diferentes de materialização com finalidades contrárias, configurando a disputa essencial entre o contrato mercantil privado e a fraternidade dos setores oprimidos.

A partir de meados do século XX e até hoje, sem a força organizada das classes populares, o setor proletário vem sendo atropelado pelos imperativos econômicos da ordem capitalista, causando insegurança e favorecendo a crescente violência social. Especialmente nas últimas décadas do século $X X$, o que se observa é a emergência de uma tendência 


\section{RevistAleph}

ideológica de pensar o sujeito como algo desprovido de conexão com suas condições históricas e estruturais de existência. Trata-se de um tipo de existência passiva (TERRA, 2012) que, segundo Claudia Alves (2010), retira do sujeito o sentimento de pertencimento e a possibilidade de participação nos espaços de poder de decisão nos âmbitos políticos, culturais e sociais.

Milton Santos (2007) afirma que os processos "globalitários" contemporâneos transformaram a flexibilidade (expressão santificada pelos seguidores da economia de mercado) em motivo comportamental de nossa vida social. O receituário neoliberal não se limitou a adequar os Estados e suas instituições às novas necessidades do capital globalizado: através de um tipo de autorregulação heterônoma, a precariedade e a incerteza das condições materiais de vida tornaram as relações sociais bastante tímidas - e as relações humanas extremamente frágeis.

A globalização do sistema de [anti]valores neoliberais baseado no individualismo, no consumismo e na competitividade, como processo hegemônico, mobiliza uma intensa dinâmica de desintegração social. Semeraro (2011, p. 470) aponta a soberania absoluta do indivíduo (burguês) na qual o Estado - ao invés de garantir a justiça social e a universalização de direitos - é posto a serviço desse, impondo "uma concepção onde o indivíduo é considerado como ser social, consciente e ativamente responsável por um Estado que forma a 'comunidade de cidadãos livres'".

O que se faz necessário frente a essa realidade é a fundação de um novo modelo democrático com uma reinvenção e renovação da democracia ou, mais bem, sua real democratização, instituindo aquela a que se chama de "alta intensidade", protagônica ou participativa: uma socialização radical que promova a soberania popular, a participação mais do que a representação ou delegação de responsabilidades nos rumos da vida social e o protagonismo dos sujeitos políticos coletivos. Tratando-se de um ator social totalmente isolado, o indivíduo não tem a força política necessária para reivindicar e ampliar seus direitos, para fazer de seu protesto uma proposta a ser incluída na agenda política da sociedade. É necessário, portanto, repensar que sujeito é esse capaz de empreender a tarefa (contínua e incessante) de democratização da democracia. Abreu (2008) afirma que tal processo requer a reconstrução de um movimento social popular baseado na consciência de classe, como bloco histórico dotado de projeto e força contra-hegemônicos. E, certamente, a 


\section{RevistAleph}

reconstrução e o fortalecimento da identidade de classe oprimida não é apenas possível, mas provável, já que tem uma materialidade real. De fato, as conquistas na implementação dos maiores valores do processo civilizador que moveram mulheres e homens por mais de dois séculos (liberdade com equidade e justiça social), não devem nada ao movimento histórico do capital. Desde este ponto de vista, reinaria somente a [in]justiça privada, a divisão desigual dos meios de subsistência e de poder, a competição desenfreada pela sobrevivência, o estranhamento entre indivíduo e sociedade e a alienação universal dos atributos humanos.

Para Gramsci (1991, p.137), uma coerente "democracia política tende a fazer coincidir governantes e governados" e, portanto, tem como modelo um autogoverno geral e o crescimento cultural de todos - existindo, nesse processo, a possibilidade de que esse tipo de democracia abra a perspectiva do socialismo. O autor aponta para a superação da sociedade de classes na medida em que supõe e exige que os setores subalternos estejam preparados para assumir a posição de governantes, para deixar sua condição de classe dominada. Os sujeitos se formem como protagonistas e propositivos que mantenham suas práticas sociais baseadas em valores orientados pelos princípios básicos de Liberdade e Justiça Social, é, portanto, condição sine qua non para levar a cabo o processo de construção de um projeto popular de sociedade radicalmente democrática.

Para tanto, deve-se pensar o Estado como um campo institucional a ser "disputado, recriado e dirigido coletivamente" (SEMERARO, 2017) de forma ética e educadora, a partir do protagonismo dos sujeitos políticos coletivos, das necessidades concretas da maioria da população e dos anseios da classe trabalhadora. Nas palavras de Gramsci, trata-se da necessidade de “(...) formular a definição mais radical de democracia que elimina a separação e a superioridade estabelecida entre dirigentes e dirigidos" (apud LOLE, GOMES \& DEL ROIO, 2017) a fim de engendrar o processo de construção de uma sociedade autodeterminada, a partir da qual se possa estabelecer "não apenas um 'autogoverno dos produtores associados', mas se socializem também a política e todas as instituições públicas" (SEMERARO, 2017, p.49).

Gramsci (Q13 Apud SEMERARO, 2017) aponta que o mundo moderno não pode ser reduzido a uma suposta vitória hegemônica da burguesia, pois é também a época histórica em que se forjaram sujeitos coletivos populares os quais, através de lutas, resistências e revoluções, deram um novo rumo à história. E, de fato, presenciamos atualmente algumas 


\section{RevistAleph}

experiências nesse sentido. O comprova o crescente protagonismo de movimentos sociais de caráter popular historicamente explorados que, por meio de uma dinâmica de luta por justiça social põem em funcionamento experiências de disputa hegemônica, nos níveis local e regional, dentro e fora do campo institucionalizado. São movimentos populares heterogêneos, diversificados, mas que compartilham o compromisso de criar o poder democrático de forma imediata e as suas reivindicações, contundentes e controvertidas, defendem uma democracia participativa como resposta às privações geradas pela globalização.

Observa-se, no interior dos movimentos populares, um tipo de atuação política de múltiplos sujeitos políticos coletivos autônomos (e pedagógicos) que está estabelecendo novas formas de relacionamento social, tecendo redes de confiança entre os mais diversificados indivíduos, superando a atomização e a fragmentação social engendradas pela globalização da ideologia neoliberal do realizar-se privadamente. Nas palavras de Coutinho (1979, p. 38) essa síntese política "[...] é imprescindível se não se quer que esses sujeitos coletivos sejam coagulados ao nível da defesa corporativista de interesses puramente grupais e particularistas, reproduzindo assim a atomização da sociedade civil que serve objetivamente à dominação burguesa".

Tais processos de ressociabilização ou, ainda, de sociabilização da contraordem (CALDART, 2007), têm encontrado espaço privilegiado nos movimentos populares, uma vez que a dinâmica de luta dos mesmos permite a recognição e a reinvenção de si e da sociedade, base do processo formativo da humanidade nos sujeitos. Caldart (2007) assevera que os movimentos populares constituem, neste sentido, um "princípio educativo", um "todo educante" que não ensina, mas problematiza e reinventa valores, criando uma nova cultura de cultivo da humanidade, através do aprendizado coletivo das possibilidades da vida. A dinâmica da luta por justiça social corresponde, decerto, a um processo educacional, pois pressupõe a aprendizagem, na ação transformadora, de novas formas de relações sociais no seio da sociedade civil.

\section{O mutirão na Ocupação Manoel Congo: dimensão político-educativa}

Os excluídos se educam, sobretudo, Nas lutas de resistência Miguel Arroyo (2000, p.08). 
Para Caldart (2007), abordar o sentido educativo de um movimento popular ou prática social requer a adoção de uma determinada concepção de educação. Na mesma linha, Arroyo (2000) assevera que a fim de visualizarmos os processos formativos no interior de um movimento popular devemos recuperar matrizes constitutivas da teoria pedagógica, assumindo uma concepção mais universal da educação, isto é, atentando para a universalidade da ação educativa. Este olhar permite ampliar o conhecimento em relação ao conceito de humanização e processo educativo situando-os dentro de desafios históricos concretos. Aprimorar e assumir o conceito dialético da educação - enquanto processo social que acontece através das próprias relações que são constituídas - significa acompanhar de forma clara a visão de complexificar as relações de produção e historicizando também a área de conhecimento pedagógico.

O resgate da relação essencial entre educação e humanização pressupõe (re) associar teoria e prática, trabalhos material e intelectual. Tal práxis social, orientada para a formação integral do ser humano e para a construção de uma sociedade orgânica (SEMERARO, 2017), requer a destruição da educação dualista baseada na tradição de cunho elitista na qual um pequeno grupo de privilegiados é concedida a prerrogativa de filosofar e assumir o papel de intelectuais na sociedade. Trata-se de reconhecer a possibilidade real de que todo e qualquer sujeito é capaz de desenvolver-se como subjetividade ativa, organizando-se politicamente como uma força criativa das classes subjugadas (SEMERARO, 2017) - o que, em termos gramscianos, significa assumir que "todos são filósofos" e que cada indivíduo pode tornar-se "intelectual orgânico" de uma coletividade e deve conquistar o papel de "dirigente" de sua própria vida. Os novos movimentos populares, através de suas ações coletivas, aparecem como espaços de fermentação desse processo: neles, podemos vislumbrar alguns dos elementos que compõem a filosofia da práxis como "expressão das classes subalternas que querem educar a si mesmas na arte do governo" (GRAMSCI, Q10, §41 Apud SEMERARO, 2014, p.141). Assim, o que se faz necessário, segundo Coutinho (1979, p.37), é a criação de:

(...) mecanismos de representação direta das massas populares (associações, sindicatos, associações profissionais, comitês de empresa e de bairro, etc.), mecanismos através dos quais essas massas populares e em 


\section{RevistAleph}

particular a classe operária - se organizam de baixo para cima e constituem aquilo que poderíamos chamar de sujeitos políticos coletivos.

O Movimento Nacional de Luta por Moradia (MLNM) pode ser visualizado como um desses sujeitos. Na cidade do Rio de Janeiro há, atualmente, cerca de 30 ocupações urbanas coordenadas pelo MLNM. No presente trabalho analisamos uma dessas, a Manuel Congo, localizada na Cinelândia, ao lado da Câmara dos Vereadores da capital fluminense. A análise, além de bibliográfica, foi realizada a partir de entrevista semiestruturada que fizemos a uma das coordenadoras e moradora da ocupação, que participou e ainda participa ativamente do planejamento e organização da mesma.

No dia 28 de outubro de 2007 cerca de 100 famílias ocupam o prédio do INSS (Instituto Nacional do Seguro Social), abandonado desde 1996. As famílias vinham se reunindo há um ano, a fim de discutir a possibilidade de se ocupar esse prédio específico. Havia uma grande preocupação em relação ao ato da ocupação naquele edifício, uma vez que no ano de 2005 um grupo anarquista organizado tentou ocupa-lo e foi violentamente reprimido pelo Estado, o qual utilizou de diversos aparatos (atiradores de elite, helicópteros da Polícia Federal, derrubada de paredes, detenções, etc.) para desocupar o prédio. A decisão de ocupá-lo foi conflituosa, porém no dia $1^{\circ}$ de outubro de 2007 (no Dia Internacional de Luta pelo Habitat) decidiu-se de forma unânime que realizariam o ato, de que ali resistiriam e nas palavras de nossa entrevistada - "só sairiam mortos". As famílias entram à noite, trocam os cadeados e lá permanecem - sem luz, água, ou qualquer infraestrutura. Já na madrugada do ato da ocupação há uma tentativa de despejo violento por parte da Polícia Militar do Estado do Rio de Janeiro (PMERJ), a qual atua de forma truculenta e terrorista, tentando entrar no prédio de maneira abrupta, agredindo verbalmente as famílias, ameaçando-as de todas as formas possíveis. Apesar do terror psicológico, sofrido por todos, mas afetando principalmente as crianças, os ocupantes permanecem no edifício, tentando abrigar-se no terraço do mesmo. Resistem. Por tratar-se de um prédio federal, a PMERJ recua. Porém, no dia seguinte, o INSS entra na Justiça Federal (JF) com um pedido de reintegração de posse. Após muita luta e disputas judiciais, conseguem negociar a não-desocupação junto ao Ministério das Cidades para paralisar a ação de reintegração. Importante notar que a atuação da "Justiça" neste episódio foi deplorável e totalmente arbitrária, inclusive escondendo o processo do grupo de advogados dos ocupantes. Criam uma associação para lograr a posse, 


\section{RevistAleph}

permitida apenas, nesse caso, a pessoas jurídicas. Com base na lei constitucional que define a função social da propriedade, conseguem a concessão real de uso em nome da Associação. A Brigada de Habitabilidade e Segurança do MNLM faz o reconhecimento e mapeamento da área, e começa a delinear o projeto para o edifício. Inicialmente todo o espaço é coletivizado, porém busca-se um tipo de equilíbrio entre o individual (moradias) e o coletivo (espaços para formação e geração de renda).

Atualmente, ocupam o prédio 42 famílias e 120 moradores. As obras, realizadas na forma de mutirões autogestionados, estão orientadas para criarem os seguintes espaços: do 3ㅇ ao 10 ㅇ andar estão sendo construídas as moradias, as quais serão individuais, mas com interesse coletivo, garantindo a privacidade dos ocupantes, porém impedindo a mercantilização das mesmas (compra, venda e locação). $O$ térreo do edifício está destinado a uma Casa de Cultura com a criação da "Casa de Samba Mariana Crioula" e um pequeno restaurante a fim de gerar trabalho aos ocupantes e a renda necessária para a manutenção do prédio. No segundo andar a ocupação contará com um auditório para formação geral (cursos educacionais, capacitação e atualização profissional, além de assembleias e reuniões), com um espaço para a ciranda infantil (baseada na perspectiva do pedagogo Paulo Freire) e, inclusive, com a construção de um pequeno salão de beleza, também para geração de trabalho e renda - e considerando que a maioria dos ocupantes é de mulheres. Aliás, todo o projeto foi pensado a partir do perfil específico dos ocupantes, levando em conta as particularidades do grupo e de seus integrantes.

Até o momento há algumas moradias finalizadas, mas todas as famílias permanecem morando no local. Apesar do grande número de ocupantes, não há chaves para as portas dos apartamentos. Apenas as destinadas a entrar no edifício, às quais todos - excetuando as crianças - têm acesso. A organização é feita de forma a suscitar a responsabilização comum do espaço e das relações humanas ali desenvolvidas. Há um escritório, uma ciranda infantil improvisada e quartos também improvisados. As obras têm sido feitas e o projeto tem sido pensado coletiva, em forma conjunta e horizontal. Todos os dias de manhã, durante uma hora, debate-se os rumos do projeto. Não há hierarquias entre os mutirantes (os capacetes que usam são todos da mesma cor), que planejam e fazem as refeições junto a todos. Morar ali é um desafio que as famílias enfrentam diariamente, já que o local se assemelha, ainda, a um grande canteiro de obras. Resistem, nas palavras de nossa entrevistada, pois 


\section{RevistAleph}

"desconstroem, na vivência cotidiana, os valores do ter, construindo valores do ser". Ainda segundo a ocupante, o desafio é precisamente "fazer o trabalhador mutirante compreender a experiência do trabalho emancipado, além do trabalho alienado" - e, acrescentamos, sua dimensão educativa.

No cenário atual de hegemonia consolidada, o processo de ampliação e de universalização dos direitos, via institucional, vem perdendo seu ânimo e força histórica. Como consequência e em nome do avance global do capital, são continuamente abandonados os compromissos estatais com o bem-estar da vida social. Se é certo que as práticas históricas de resistência e luta das classes subalternizadas foram a efetiva força democratizante de nossas sociedades, é também inquestionável o fato de que a materialidade dessa mesma força humana jamais poderá ser limitada aos processos políticos eleitorais e puramente institucionais. Nas palavras de Coutinho (1979, pp.37-38), "a essa socialização objetiva da participação política deve corresponder, em medida cada vez maior uma socialização dos meios e dos processos de governar o conjunto da vida social. " Para Abreu (2008, p.316), é na reconstrução da identidade social fundada na vida daqueles que trabalham ou desejam viver de seu trabalho, no movimento organizado desses sujeitos, que encontramos "terra firme" para a construção de uma democracia socialista.

Gohn (2005) afirma que o processo de [re] criação da identidade dos setores explorados, ou ainda, da identidade de classe, só se torna possível a partir da vinculação do sujeito com um coletivo diversificado, culturalmente heterogêneo, mas que transmita um projeto comum e alternativo de organização social. A autora afirma que o coletivo deve ser o cenário, o espaço de construção das vontades, "através do pluralismo de ideias, de seus embates, e da formulação de linhas comuns que possibilitam a canalização das vontades individuais em vontades coletivas" (GOHN, 2005, p.107). Urge, portanto - como assevera Coutinho (1979, p.44) incorporar as amplas maiorias ao cenário político:

\footnotetext{
Ampliar a organização e a articulação desses vários sujeitos políticos coletivos de base e, ao mesmo tempo, lutar por sua unificação (respeitadas sua autonomia e diversidade) num poderoso bloco democrático e popular [...] é um passo decisivo no sentido de criar os pressupostos para o aprofundamento e a generalização do processo de renovação democrática.
}

Trata-se de disputar e de (re)criar a instituição do Estado e o poder político em uma relação de superação dialética entre a democracia socialista (radical ou de alta intensidade) e 


\section{RevistAleph}

da democracia liberal (burguesa), eliminando, conservando e elevando a um nível superior as conquistas da segunda (COUTINHO, 1979, p. 40-44), abrindo a possibilidade concreta de "intensificar a luta pelo aprofundamento da democracia política no sentido de uma democracia organizada de massas, que desloque cada vez mais 'para baixo' o eixo das grandes decisões hoje tomadas 'pelo alto'."

\section{Considerações}

Analisando as formas de sociabilidade das atividades cotidianas da ocupação, é possível afirmar que os valores e conhecimentos que o Movimento mobiliza, especificamente nessa ocupação, podem ajudar na mudança comportamental dos sujeitos implicados no mesmo, desenvolvendo uma postura crítica e participativa que permite a construção de formas mais democráticas de organização coletiva. As atividades envolvidas na reforma estrutural do edifício ocupado, além de produzirem uma moradia digna para a população envolvida na luta por sua posse, parecem estar possibilitando o desenvolvimento e fortalecimento da consciência e prática como agentes protagonistas por meio de um trabalho participativo, horizontalizado e coletivizado, apontando para um modelo um autogoverno geral e possibilitando o crescimento cultural de todos os envolvidos. A experiência que se desenvolve na Manuel Congo converte a ocupação em um espaço de criação de novas formas de relacionamento social entre a classe trabalhadora, que estão construindo a si mesmos como sujeitos históricos ativos através do fortalecimento do sentimento de pertencimento e na mudança na forma de participação (direta) e definição dos rumos da vida coletiva por meio de assembleias, atividades laborais e trocas de experiências/vivências.

Neste estudo inicial, os valores de solidariedade, cooperação, justiça social, ética e equidade manifestam-se nas práticas cotidianas realizadas na Ocupação Manuel Congo. Encontramos indícios de que tais atividades podem ser consideradas práticas políticopedagógicas dinâmicas, dialógicas e críticas por meio da qual as pessoas se constroem a si mesmas como protagonistas do processo de desenvolvimento material e cultural de sua vida social - isto é, esses sujeitos se historicizam a si mesmo a sua própria realidade. Em outros termos, as atividades possibilitam a aprendizagem de novas formas de sociabilidade, um novo tipo de sujeito, capaz de tornar-se governante de si mesmo. 


\section{Referências}

ABREU, Haroldo. Para Além dos Direitos: cidadania e hegemonia no mundo moderno. Rio de Janeiro: Editora UFRJ, 2008.

ALVES, Claudia. Problemas da relação Educação-Cidadania na História Brasileira. In: FELGUEIRAS, M.L. \& VIEIRA, C.E. (Eds.). Cultura Escolar, Migrações e Cidadania. Porto: Sociedade Portuguesa de Ciências da Educação. 2010.

ARROYO, Miguel. Educação e Exclusão da Cidadania. In: BUFFA, E., et al. Educação e Cidadania: quem educa o cidadão? São Paulo: Cortez Editora, 2000.

BOTEGA, Leonardo da Rocha. Ocupação da Fazenda Santa Marta em Santa Maria-RS (1991-1993). Monografia. 2004. (Graduação em História do Brasil) - Universidade Federal de Santa Maria, Santa Maria.

CALDART, Roseli Salete. Pedagogia do Movimento Sem Terra. Petrópolis: Vozes, 2007.

COUTINHO, Carlos Nelson. A Democracia como Valor Universal. In: SILVEIRA, E. et al. Encontros com a Civilização Brasileira, v.9. Rio de Janeiro: Civilização Brasileira, 1979.

FORNAZIN, Henrique. Luta pela moradia na Ocupação Manuel Congo: imagens e implicações subjetivas. 2014. Dissertação. (Mestrado em Ciências Sociais) - Programa de Pós-Graduação em Ciências Sociais, Universidade do Estado do Rio de Janeiro, Rio de Janeiro. 2014.

GRAMSCI, Antonio. Os intelectuais e a Organização da Cultura. Rio de Janeiro: Civilização Brasileira, 1991.

GOHN, Maria da Glória. Movimentos Sociais e Educação. São Paulo: Cortez, 2005.

GOHN, Maria da Glória. Movimentos Sociais e a Luta pela Moradia. São Paulo: Loyola, 1991.

HARVEY, David. A Liberdade da Cidade. GEOUSP - Espaço e Tempo. São Paulo, № 26, 2009.

Disponível em: <http://www.geografia.fflch.usp.br/publicacoes/Geousp/Geousp26/09-18-

HARVEY,David.pdf.> Acesso em: 23 de dez. de 2018.

HARVEY, David. O novo imperialismo. São Paulo: Loyola. 2011.

LIGUORI, G.; VOZA, P. (Orgs.). Dicionário gramsciano (1926-1937). São Paulo: Boitempo. 2017.

LOLE, Ana.; GOMES, Victor Leandro; DEL ROIO, Marcos. (Orgs.). Gramsci e a Revolução Russa. Rio de Janeiro: Mórula Editorial. 2017.

LUCE, Mathias Seibel. Teoria Marxista da Dependência (TDM): problemas e categorias, Uma visão histórica. São Paulo: Expressão Popular. 2018.

MARX, Karl. A Questão Judaica. Lusofia Press, 2008. Disponível em:

$<$ http://www.lusosofia.net/textos/marx_questao_judaica.pdf $>$. Acesso em 2 de Jan. de 2019. 


\section{RevistAleph}

MARX, Karl. Introdução à contribuição à crítica da Economia Política. Luta Socialista, 2012.

Disponível em:

http://lutasocialista.com.br/livros/MARX\%20E\%20ENGELS/MARX,\%20Karl.\%20Contribui\%E7\%E30\% 20\%E0\%20Cr\%EDtica\%20da\%20Economia\%20Pol\%EDtica.pdf>. Acesso em 15 de fev. 2019.

PEREIRA, João Márcio Mendes \& PRONKO, Marcela. A demolição de Direitos. Um exame das políticas do Banco Mundial para a educação e a saúde (1980-2013). Rio de Janeiro, EPSJV-Fiocruz. 2014.

SETÚBAL, Mariana (Orgs.). Pensamento crítico e movimentos sociais: diálogos para uma nova práxis. São Paulo: Cortez, 2005.

SANTOS, Eladir. F. N. FAFERJ - Organização, resistência e luta contra as remoções. In: XI Congresso Luso-Afro-Brasileiro (XI CONLAB), 2011, Salvador. XI CONLAB 2011, 2011.

SANTOS, Milton. A urbanização brasileira. 2. ed. São Paulo: Hucitec, 1995.

SEMERARO, Giovanni. A Concepção Revolucionária da Política em Gramsci: uma análise do Caderno 13. Movimento Revista de Educação. Faculdade de Educação - UFF. Niterói, ano 4, n.6, pp.34-53, jan/jul. 2017.

SEMERARO, Giovanni. Filosofia da práxis e as práticas político-pedagógicas populares. Educação e Filosofia, Uberlândia v. 28, n. 55, p. 131-148, 2014.

SEMERARO, Giovanni. A 'utopia' do Estado Ético em Gramsci e nos movimentos populares". Revista de Educação Pública, [S.I.], v. 20, n. 44, p/. 465-480, jun. 2011. ISSN 2238-2097.

SILVEIRA, Pedro Sergio da. O Movimento Nacional de Luta pela Moradia (MNLM) e a luta pela reforma urbana na Nova Santa Marta, RS. Monografia. 2014. (Licenciatura Plena e Bacharelado em História) - Centro de Ciências Sociais e Humanas. Universidade Federal de Santa Maria, Santa Maria.

TERRA, Paulo Cruz. Cidadania e Trabalhadores: Cocheiros e Carroceiros no Rio de Janeiro (18701906). Tese. 2012. (Doutorado em História). Faculdade de História - Universidade Federal Fluminense, Niterói.

Data do envio: $30 / 05 / 2020$.

Data do aceite: $17 / 06 / 2020$. 